\title{
Possibility of applying unmanned aerial vehicle and thermal imaging in several canopy cover class for wildlife monitoring - preliminary results
}

\author{
Dede Aulia Rahman ${ }^{1,2 *}$ and Yudi Setiawan ${ }^{1,2}$ \\ ${ }^{1}$ Department of Forest Resources Conservation and Ecotourism, Faculty of Forestry and \\ Environment, IPB University (Bogor Agricultural University), Kampus IPB Darmaga Bogor 16680 \\ Indonesia. \\ ${ }^{2}$ Tropical Biodiversity Conservation Program, Faculty of Forestry and Environment, IPB University \\ (Bogor Agricultural University), Kampus IPB Darmaga Bogor 16680 Indonesia.
}

\begin{abstract}
Tropical rainforests are one of the important habitats on earth but are rarely explored because they are difficult to access, making their cryptic animals challenging to monitor. Unmanned aerial vehicle (UAV) with thermal infrared imaging (TIR) technology is gaining entry into wildlife research and monitoring. The researcher tested the possibility of applying DJI Mavic 2 Enterprise Dual with FLIR as aerial survey platforms to wildlife in the five tree density classes in the IPB University Campus. To assess the effectiveness of using drones in detecting wildlife, the researcher measured the optimum flying height, sound level, temperature, and optimum flight time in each canopy cover class. The optimum height for animal detection is $<50 \mathrm{~m}$ HAGL with a sound level that animals can still tolerate. Wildlife detected had body temperatures around $27^{\circ} \mathrm{C}$ and were conspicuous in the thermal infrared imagery at night and early morning when the forest canopy was cool $\left(15-27^{\circ} \mathrm{C}\right)$, but were difficult to detect by mid-day. By that time, the direct sunshine had heated up canopy vegetation to over $30^{\circ} \mathrm{C}$. Species were difficult to identify from thermal infrared imagery alone but could be recognized from synchronized visual images taken during the daytime.
\end{abstract}

\section{Introduction}

In the last decade, the use of unmanned aerial vehicles (UAVs) to detect, count, and monitor wildlife has increased, and the development of large to small-dimensional UAVs with all the improvements is continuously being made. Unmanned aerial systems (a.k.a. drones) are capable of moving fast, scanning forests from top to bottom and are very promising for expanding the scale of canopy surveys that are very useful in studying wildlife ecology. Drone imagery has proven useful for wildlife surveys in open areas, for example, guanaco [1], Artic birds [2], kangaroo [3], caribou [4], waterfowl [5], hippos [6], and crocodile [7]. Meanwhile, for animals living in tree canopies, UAVs are not widely used because of the difficulty of visually detecting these animals with standard aerial imagery. In the early period

\footnotetext{
* Corresponding author: dede.auliarahman@gmail.com
} 
of their development, drones could only be used in daytime monitoring since this technology being developed relies on sensors that effectively collect imagery at visual wavelengths and were often inefficient at spotting animals that had developed visual camouflage to avoid detection by predators [8].

The use of thermal infrared (TIR) imagery was initiated in the 1960s by [9] and is potentially being used to increase wildlife detection. Nevertheless, as do planes needed to get the aerial footage [10], TIR was not very popular in its early development because it was classified as an expensive technology and was not useful for detecting wildlife under a thick forest canopy [11]. Nowadays, interest in using thermal for wildlife surveys increases along with technological advances in thermal infrared sensor miniaturization of drone size and reduction in this technology's price. However, for example in a study by [12] found that the main challenges of applying thermal infrared images in aerial surveys are difficulty in species identification due to the limitations of resolution of the TIR camera, high dependence on weather, and regulations that limit drone operations to the visual line of sight. In its development, TIR technology has been used by [13] and found thermal imagery has successfully detected several orangutans and proboscis monkey's group, which is entirely confirmed by ground observers. Furthermore, a terrestrial mammal such as white-tailed deer is most detectable when the background environment is coldest, especially during the early morning and late evening before sunset, both in open vegetation cover and mixed-deciduous forest from an altitude of $100 \mathrm{~m}$ above ground level [14]. The two studies above imply limitations in using TIR, especially related to the difficulty of identifying the result of thermal images, including the need for double-checking for animals was detected in an aerial survey by ground observers.

The fauna that inhabits the canopy of tropical rainforests provides a different level of difficulty than leafless deciduous forests and coniferous forests in the application of drone technology combined with thermal infrared imaging. Some of the difficulties in applying this technology are 1) thermal signatures on animals are obstructed by thick leaf cover, except when the animals are at the top of trees, 2) in high-moving species, the noise of the drone can frighten animals so that animals move or hide in a location that is difficult to detect, 3) species identification is very dependent on the quality of the image obtained. To overcome those limitations, the author conducted tests of a drone's ability with standard RGB images and radiometric thermal sensors to detect and identify wildlife in a tropical rainforest. Furthermore, this study aims to assess the effectiveness of using drones in detecting wildlife based on variables of optimum flying height, sound level, temperature (canopy, wildlife, and forest floor), and optimum flight time. If detection using UAVs is applicable, this method could be an essential tool for future detection and monitoring of wildlife in similar types of environments.

\section{Method}

\subsection{Study area}

The test flights were conducted in the natural forest remaining on the IPB University campus, Indonesia $\left(6^{\circ} 30^{\prime}-6^{\circ} 45^{\prime} \mathrm{S}\right.$ and $\left.106^{\circ} 30^{\prime}-106^{\circ} 45^{\prime} \mathrm{E}\right)$. The area of the campus is 267 ha, and the terrain is flat. Less than $40 \%$ of the area is covered by various types of trees of different age and canopy cover classes. Several trees species that dominate including mahogany (Swietenia macrophylla), rubber tree (Hevea brasiliensis), African tulip (Spathodea campanulata), white albizia (Paraserianthes falcataria), and breadfruit (Artocarpus altilis). The most common mammals in the remaining forest are long-tailed macaque (Macaca fascicularis), pangolin (Psiittacula alexandri), Malayan porcupine (Hystrix brachyura), 
Asian palm civets (Paradoxurus hermaphroditus), Javan mongoose (Herpestes javanica), as well as several species of rats, squirrels, and bats. The remaining forest is also inhabited by many birds, reptiles, amphibians, and butterflies.

\subsection{Data collection}

\subsubsection{Drone platform and sensor}

The author used DJI Mavic 2 Enterprise Dual with FLIR as aerial survey platforms (hereafter "drones"). The Mavic 2 Enterprise Dual is equipped with a standard camera and infrared sensor. Measurement of temperature in the center of the field of view is possible on an infrared camera. Images or videos recorded on the camera can be viewed either independently (just 1080P RGB or just thermal) or directly simultaneously. FLIR MSX (multispectral dynamic imaging) on the drone with an easily visible light spectrum, were able to show the heat difference between objects recorded. The two spectra that present two different views of the object recorded on each camera sensor can be seen in one view by the operator. Equipped with OcuSync 2.0, this technology can easily transmit a 1080P video even through a solid barrier with a transmission range of up to 5 miles. The time, date, and GPS location of every image or video recorded in flight are recorded on GPS timestamping. This additional data is very important information that shows the time and location of the object recorded, either in the form of images or videos. Flights can be carried out for up to 31 minutes with minimal sound and move quickly by taking advantage of DJI's efficient propulsion system. The Mavic 2 Enterprise can move at a maximum speed of $44 \mathrm{mph}$ so it can keep pace with target objects while moving. In cold weather conditions, the battery of Mavic 2 Enterprise Dual can warm up on its own, increasing its usability in a variety of weather conditions. In addition to these advantages, the Mavic 2 Enterprise also has a new "Discrete Mode", which makes it possible to turn off all the aircraft's LEDs so the user can fly it for missions that require undetectable stealth mode flight. The author used an Apple 7.9" iPad (128GB, Wi-Fi +4 G LTE) as our live-feed screen for both systems.

\subsubsection{Sampling location}

Selected areas are based on the density of canopy cover. Canopy cover variables were reflecting an increasing level of potential difficulty in detecting thermal signatures. Thermal sensor sensitivity is inversely proportional to the level of canopy cover. Canopy cover is categorized into four classes, i.e., 1) sparse - trees do not compete for light, 2) broken - there is a gap between the canopy with a width the size of one or two canopies, 3) moderate between the crowns there are narrow gaps, some of them being the size of a single tree crown, 4) full - between the tree crowns either fully touching or partially overlapping [15]. LAI measurements were carried out through digital hemispherical photography (DHP) techniques using a DSLR camera equipped with a fisheye lens and a tripod (Table 1; Fig. 1). The camera is placed on a tripod with a height of $1.3 \mathrm{~m}$ diameter at breast height (dbh) and adjusts to the terrain by leveling it. The camera is facing parallel to the direction of the tree canopy vertically upwards, and the screen's direction facing to the north [16]. 


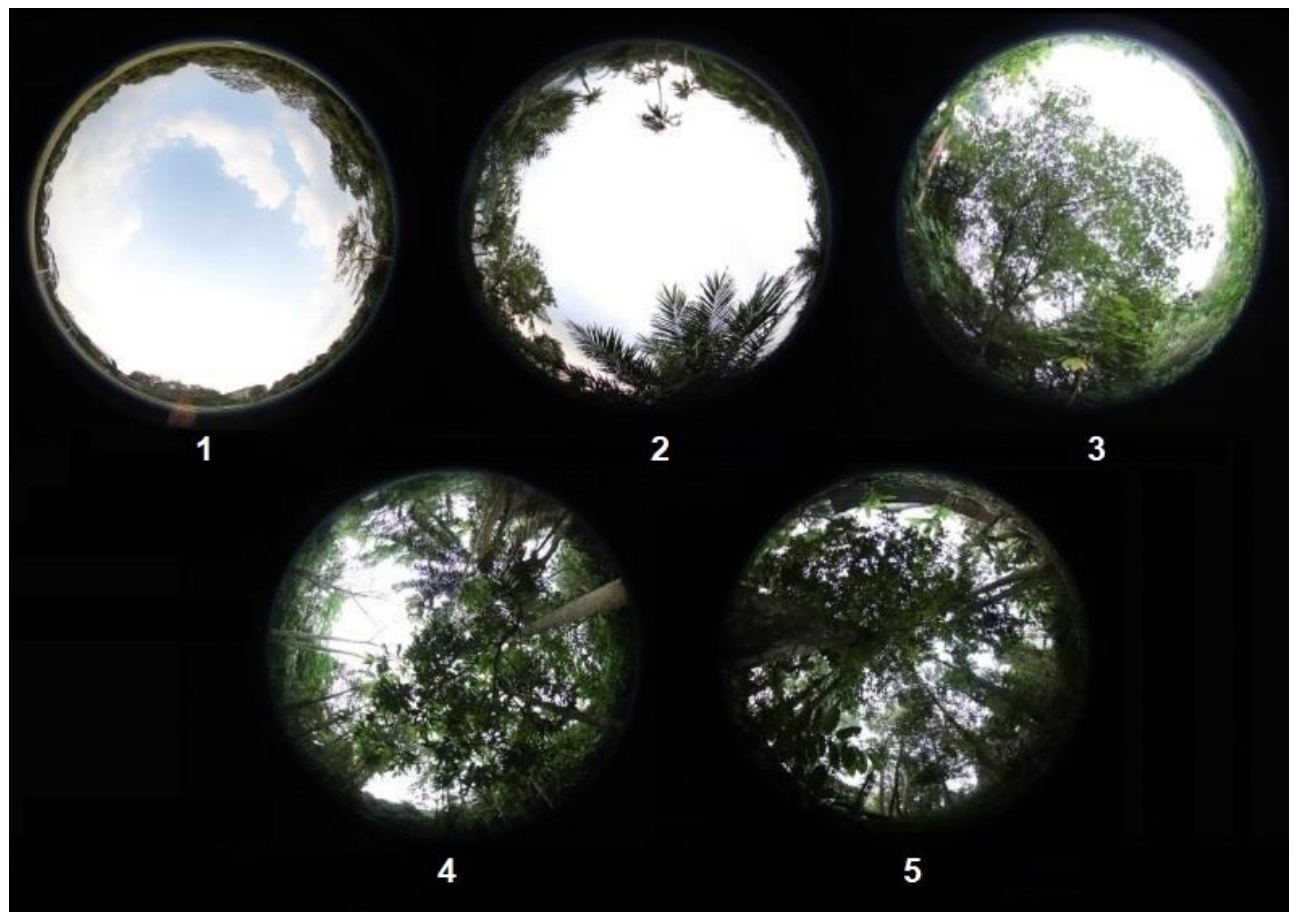

Fig. 1. Leaf Area Index (LAI) measurements in several representative locations in the study area that describe the condition of canopy cover density (Rahman and Setiawan, 2020).

\subsubsection{Flight plans and parameters}

The test flights were conducted over five square plot sample areas, which ranged in area from $30 \times 30 \mathrm{~m}$ with a total buffer area of $90 \times 90 \mathrm{~m}$ (Fig. 2). Flights were carried out from June to August 2020 ( 24 hours in each day). Ten flights were flown throughout the day, with two repetitions for each plot location to assess the effectiveness of using drones in detecting wildlife based on variables of optimum flying height, sound level, temperature (canopy, wildlife, and forest floor), and optimum flight time. The flight paths over five sample areas had the form of parallel transects positioned along the side of the square plots. To provide complete area coverage, the author designed observation paths close to each other. The UAV's technical characteristics, the relatively small field of view of the camera, and the wind conditions at the time of the survey are used as the basis for determining the parallel transect pattern in survey activities. The flight is carried out autonomously after the drone is launched, the flight path is programmed with HORIZONmp software. Through this software, the operator can monitor the drone's flight on the screen at the ground control station (GCS), including battery status information, global positioning system (GPS) coordinates, flight current speed, and altitude of the drone.

Measurement of animal detection started at an altitude of 100 m HAGL (height above ground level) and is continued by lowering the drone's altitude every $10 \mathrm{~m}$ downward until it reaches a height of $10 \mathrm{~m}$ HAGL. First, it is flown the drone vertically until it reaches a height of $100 \mathrm{~m}$, followed by flying horizontally to detect animals' presence at that altitude for 2-3 minutes, then followed by lowering the drone $10 \mathrm{~m}$ downwards with the same flight duration as the flight horizontally. This procedure is continued until the drone is at an altitude of $10 \mathrm{~m} \mathrm{HAGL}$ (Fig. 3). At each altitude, the drone pilot is shooting in video mode. 

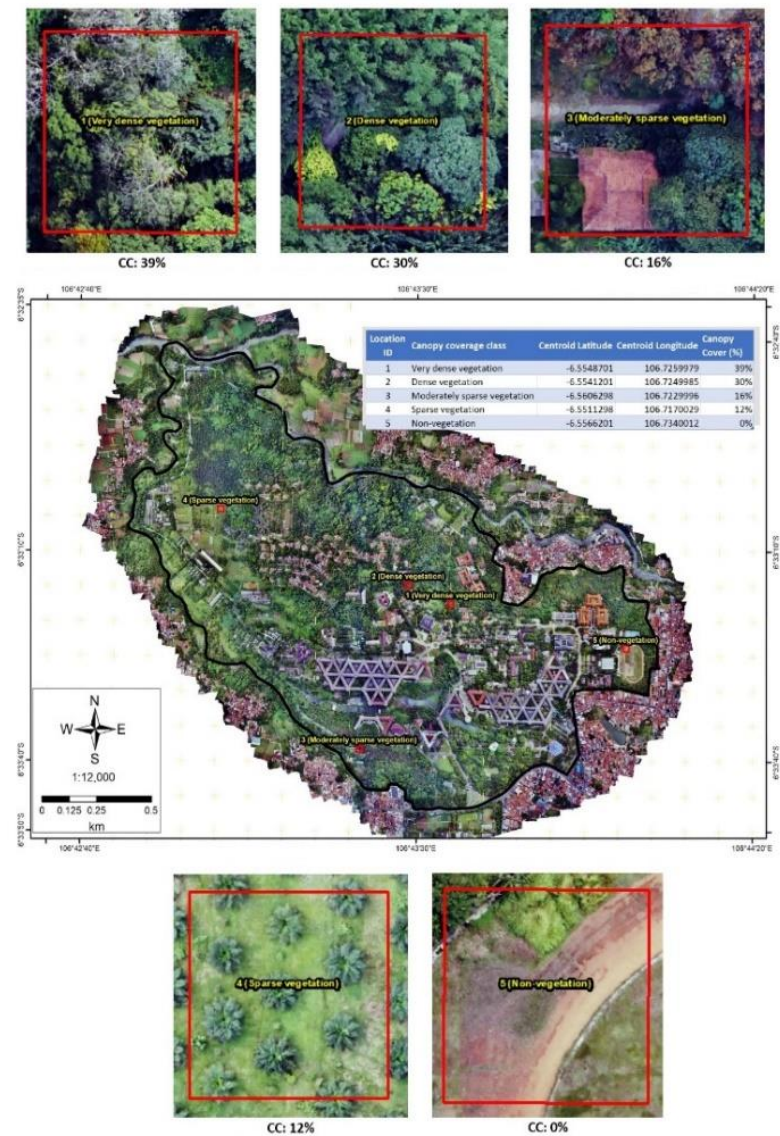

CC: $16 \%$

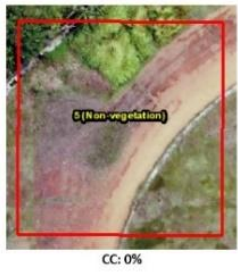

Fig. 2. Location of square plots (red line polygons) of this study area (Rahman and Setiawan, 2020).

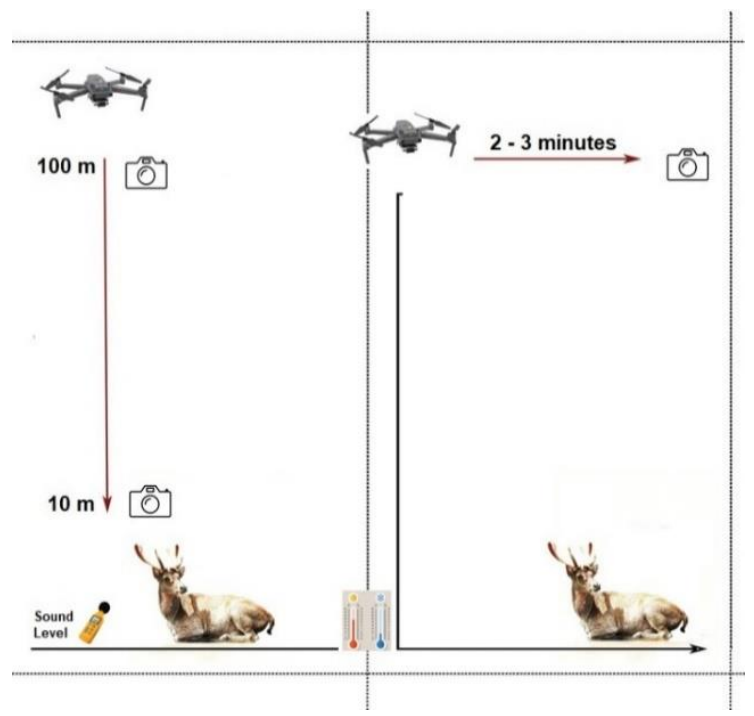

Fig. 3. Flight plans performed in each canopy cover class. The camera symbol indicates a video being taken (Rahman and Setiawan, 2020). 
At various heights then measured the optimum height of drones in detecting the presence of animals, the noise level tolerated by the animals, the temperature under the canopy by measuring the temperature using a wet and dry thermometer, the temperature of animals and environment canopy based thermal sensor on drones and the time flew optimum to detect animals. The level of noise on drones is very decisive in wildlife monitoring activities because it is related to the level of disturbance to wildlife and animal research's ethical standards. The drone sound recording results are processed using a sound analysis program to illustrate the sound intensity value.

The UAV is controlled manually by the operator during takeoff and landing using a remote control system. The total flight time varies per hour, between 20-25 minutes. UAVs are flown at an altitude of 10-100 m HAGL (height above ground level) with an average speed of 8.5-11 m s -1 (30.6-39.6 km h -1). Central square plots were filmed having each side length of $30 \mathrm{~m}$. To improve detection and estimate the size of each area surveyed, the author create a buffer width of 90 on each side along the actual flight path.

\subsection{Data analysis}

\subsubsection{Canopy cover density}

The canopy density level was analyzed by measuring the Leaf Area Index (LAI) at several representative locations in the study area. LAI calculation using Hemiview 2.1 software (Table 1).

Table 1. Area proportion for each canopy cover class.

\begin{tabular}{|c|c|c|c|c|}
\hline ID Location & Canopy cover class & LAI & Area (ha) & Percentage (\%) \\
\hline 1 & Non-vegetation & 0.246 & 17.03 & 6.90 \\
\hline 2 & Sparse vegetation & 0.456 & 54.61 & 22.11 \\
\hline 3 & Moderately sparse vegetation & 1.409 & 43.79 & 17.73 \\
\hline 4 & Dense vegetation & 1.577 & 65.59 & 26.55 \\
\hline 5 & Very dense vegetation & 1.894 & 66.02 & 26.72 \\
\hline
\end{tabular}

\subsubsection{Animal detectability and parameters effectiveness}

All images or videos generated from the 10-100 m HAGL flight on a five-square plot sample are collected and then manually checked under the same strict protocol by two trained independent observers. The protocols applied briefly consist of checking the grid overlay on each image or video, observing the image or video from left to right, and from top to bottom, enlarging the image if necessary to locate terrestrial and arboreal mammals and marking them. When a thermal signature of an individual or group of animals is detected in a sequence of video frames recorded by the drone, then the single frame with the best quality is selected and processed using VLC Media Player 2.2.4 to be extracted (http://www.videolan.org/vlc/). Furthermore, using the ImageJ program, each detected animal signature is measured in length (in pixels) and converted to centimeters by multiplying by the GSD factor ((Ground Sample Distance $=$ pixel size $($ micron $) *$ flight height $(\mathrm{m}) /$ focal length $(\mathrm{mm})$ ).

Using wild animal species reported in the literature $[17,18]$, the author classified TIR image signatures. Suppose an animal is recorded more than once or appears in groups (the group is assumed to be a single species). In that case, the longest recorded thermal signature is used as the basis for species identification. 


\subsubsection{Parameters effectiveness}

Optimum flying height, sound level, temperature (forest floor, animal, and canopy), and optimum flight time were analyzed descriptively. The optimum flying height is determined based on the ease of identifying animals based on the video produced by the drone. The tolerable sound level is based on the animal's reaction to the UAV's travel. The author classified animal's responses as 1) no reaction (the animals continued displaying the same behavior), 2) avoidance reaction (moving quickly or running away from the original location to another location that is opposite or away from the UAV or displays a posture of alertness by standing up, ears upright and directed towards the stimulus, pointing the head and neck upright observing the UAV flight movements). The optimum temperature of detection is concluded based on the comparison between the temperature under the canopy and the temperature of the animal for terrestrial species, while for canopy animals, it is compared between the temperature conditions in the canopy environment with the body temperature of the animals detected on the drone. Meanwhile, the optimum flight time is based on the number of animal detections throughout the sample area.

\section{Results and discussion}

\subsection{Animal detectability and parameters}

During all ten flights, the author registered a total of 8 thermal signatures belonging to 17 individual animals (Table 2). Using a drone with a dual-sensor in the daytime survey made it possible to use a high-resolution visual RGB sensor, which provides additional information to identify canopy animals detected by the thermal sensor. Nighttime surveys are more likely to detect terrestrial animals with a more solid thermal image but with lower pixel resolution (Javan deer; size 134-205 cm, thin and long with a distinctive head; lengths 6-9 pixels, with total areas of 31-52 pixels). However, species identification can still be made based on their size, morphology, and unique movements (Fig. 4). However, the measurement of recorded animal signatures indicates that body length cannot be the sole criterion for species identification, as the range of animal body lengths may overlap with other animals. This was not a critical issue in our survey since only one deer species inhabits our sample areas.

To overcome this limitation, increasing the resolution of the TIR sensors used in drones is one solution that can be chosen. TIR sensors with a much higher resolution are currently available in the market and might be more affordable in the future. In our survey, the TIR sensor used was low $(640 \times 360)$ compared to the existing TIR sensors $(640 \times 480$ or $1024 \times$ 768 , FLIR T1030sc) being standard to monitor wildlife. Furthermore, another option is to use machine learning techniques that can identify animals with thermal signatures that often have too little detail [19-22].

In the initial period of testing, the author flew the drone at an altitude above $100 \mathrm{~m}$ HAGL. This altitude allows a larger area to be surveyed quickly. But unfortunately, this advantage comes at the expense of thermal sensor resolution and the canopy and terrestrial animals' detection. The thermal image sensor used is FLIR Lepton with a low resolution for the animal survey. The level of detail that appears to drop sharply at an altitude $>100$ m HAGL above the canopy. The author found that drones with a flying altitude of $<50 \mathrm{~m}$ HAGL were good for detecting and recognizing animals. However, flying at lower altitudes takes longer flight time to survey the same area and increases the risk of disturbing the animals [1]. 
Table 2. Sample areas with different canopy cover, number of individuals/groups, and parameter detection.

\begin{tabular}{|l|c|c|c|c|c|}
\hline \multirow{2}{*}{ Parameter } & \multicolumn{5}{|c|}{ Canopy cover class } \\
\cline { 2 - 6 } & $\begin{array}{c}\text { Non- } \\
\text { vegetation }\end{array}$ & $\begin{array}{c}\text { Sparse } \\
\text { vegetation }\end{array}$ & $\begin{array}{c}\text { Moderately sparse } \\
\text { vegetation }\end{array}$ & $\begin{array}{c}\text { Dense } \\
\text { vegetation }\end{array}$ & $\begin{array}{c}\text { Very dense } \\
\text { vegetation }\end{array}$ \\
\hline Area (ha) & 17.03 & 54.61 & 43.79 & 65.59 & 66.02 \\
\hline $\begin{array}{l}\text { Number of detected } \\
\text { individuals/groups }\end{array}$ & 0 & 0 & 3 & 4 & 1 \\
\hline $\begin{array}{l}\text { Sighting rate } \\
\text { (detection/ha) }\end{array}$ & 0 & 0 & 0.07 & 0.06 & 0.02 \\
\hline $\begin{array}{l}\text { Flying height (m } \\
\text { HAGL) }\end{array}$ & - & - & $20-30$ & $30-40$ & 40 \\
\hline Sound level (dB) & - & - & $52.2-61.4$ & $53.3-60$ & $48.2-61.9$ \\
\hline $\begin{array}{l}\text { Forest floor } \\
\text { temperature when } \\
\text { animals are detected } \\
\left({ }^{\circ} \mathrm{C}\right)\end{array}$ & - & - & $25-32$ & $25-30$ & $23-29$ \\
\hline $\begin{array}{l}\text { Animal temperature } \\
\left({ }^{\circ} \mathrm{C}\right)\end{array}$ & - & - & $21-33$ & $24-35$ & $24-34$ \\
\hline $\begin{array}{l}\text { Canopy temperature } \\
\text { when animals are } \\
\left.\text { detected ( }{ }^{\circ} \mathrm{C}\right)\end{array}$ & - & - & $12: 43,17: 20$, & $\begin{array}{l}06: 58, \\
07: 22, \\
17: 13, \\
17: 44\end{array}$ & $22: 10$ \\
\hline \begin{tabular}{l} 
Flight time (hour) \\
\hline
\end{tabular} & - & & & & $20-22$ \\
\hline
\end{tabular}

Increasing detection by lowering the drone's height certainly has implications for increasing the sound emitted by drone engines. Noise is a form of disturbance for wildlife; reducing disturbance for animals in a survey activity is very important to reduce the impact on the population and increase detection. Noise causes animals to move downwards away from the drone and then hide under foliage to block their thermal profile. Our research found that animals are not disturbed when the drone is $30-40 \mathrm{~m}$ above the forest floor or canopy, but instead, their response varies when the drone is $<30 \mathrm{~m}$. The long-tailed macaque showed the reaction of bobbing its head upwards following the drone's flying direction at an altitude of $20 \mathrm{~m}$, but within a few minutes, they returned to their normal activities. This reaction probably because the sound produced by our drones (48.2-61.9 dB) is still within their tolerance limits. The sound intensity value $\leq 60 \mathrm{~dB}$ indicates that the drone has a low noise level or, according to [23] and [24], is considered not to impact wildlife negatively.

\subsection{Performance in different habitats}

Animals were detected in three canopy cover classes (Table 2). In very dense vegetation, animals are relatively visible in the treetops and easily detected (Fig. 4A, B). Contrary, tree canopy with dense vegetation is a significant barrier between the thermal sensor and the animal, especially when the animals are on the canopy branches. In moderately sparse vegetation, signs from animals are easier to detect, even when under tree canopy - as the UAV moves over the forest, parts of the ground previously covered by certain tree crowns become visible to the camera (Fig. 4C). The author would not recommend using lowresolution UAV thermal surveys in densely vegetated forests unless combined with groundbased surveys. The author were unsuccessful in detecting the animals at non-vegetation and 
sparse vegetation sample locations; however, based on the high-temperature contrast between the ground and the temperature indicated by the thermal sensor (Fig. 5), the author guess that UAV technology with thermal imagery sensors will be effective if used at night.

The low levels of sightings with animals in our survey may be related to rapid landscape change. The variety of habitat types on the IPB University Campus supports the existence of various types of animals [18]. Even so, humans' presence associated with the use of the same space has had a major influence on the existence of animals on the IPB Campus. The fast and rapid pace of physical development and land use at the IPB Campus is a necessity. The previously vegetated land is now turning into a built-up area, resulting in loss of habitat for various types of animals.

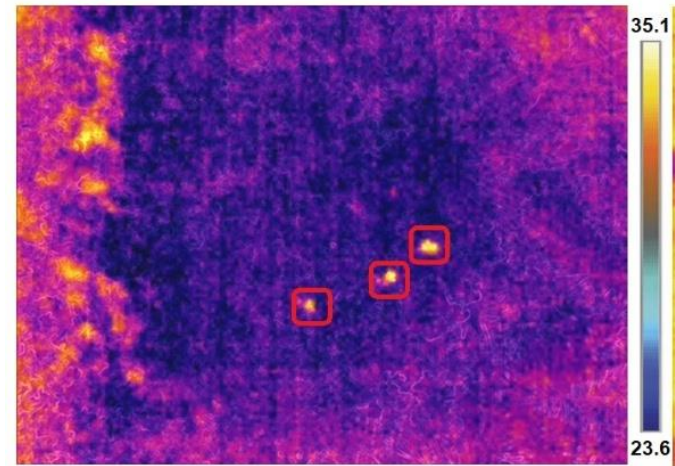

A

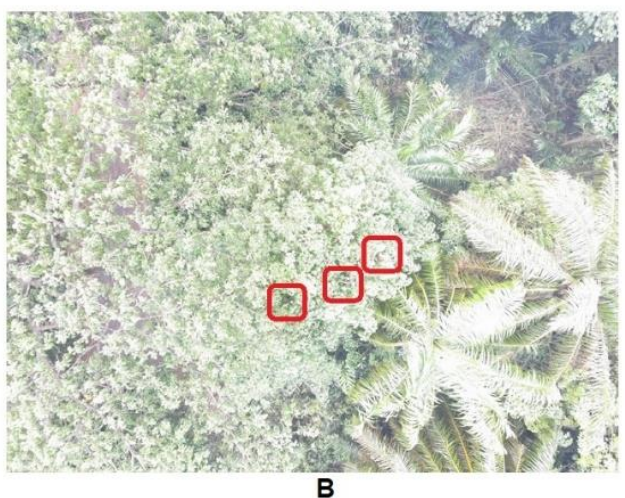

Fig. 4. Long-tailed macaque captured by A) thermal infrared and B) visual RGB sensors on drones flying horizontally at 17:13, and C) Javan deer detected by thermal infrared at 22:23 (Rahman and Setiawan, 2020).

\subsection{Effective time of survey}

The optimal detection time for an animal is closely related to the temperature contrast between the animal and its environment. Our study found that at night and early morning, when the canopy has cooled, the animals' thermal image is more visible. Our findings correspond with suggestions for surveys in other habitats [25]. An animal's body temperature is generally at least $3{ }^{\circ} \mathrm{C}$ warmer than their environmental conditions at night and in the early morning, increasing the effectiveness of the thermal sensor [26]. Conversely, when it is daytime when the sun starts to heat the environment, thermal images of animals tend to be obscured by environmental temperature conditions. The top canopy temperature recorded by 
the thermal sensor when the animal was detected ranged from $15^{\circ} \mathrm{C}$ for shaded leaves from 06:58 to $30^{\circ} \mathrm{C}$ for branches that were not covered by leaves at $17: 13$.

Furthermore, the temperatures in the upper canopy and forest floor warmed rapidly after dawn under intensive insolation. The author recorded peak temperatures for the upper canopy and forest floor between 12:00 and 14:00 with temperatures ranging from $28-39{ }^{\circ} \mathrm{C}$ and $26-33{ }^{\circ} \mathrm{C}$, respectively. This causes the temperature range between the animal and its environment to become narrower, thereby reducing the thermal sensor's effectiveness, which is very dependent on the temperature contrast of the animal with the background environment.

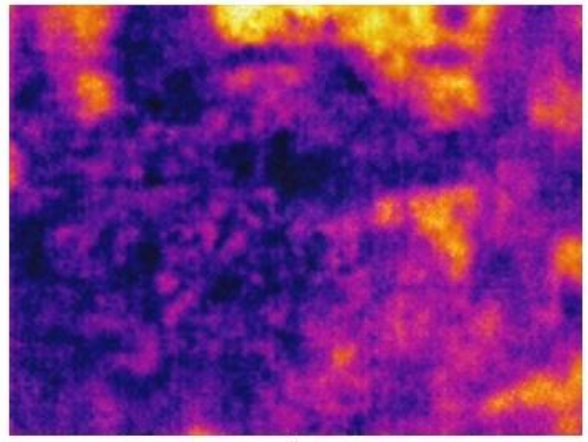

A

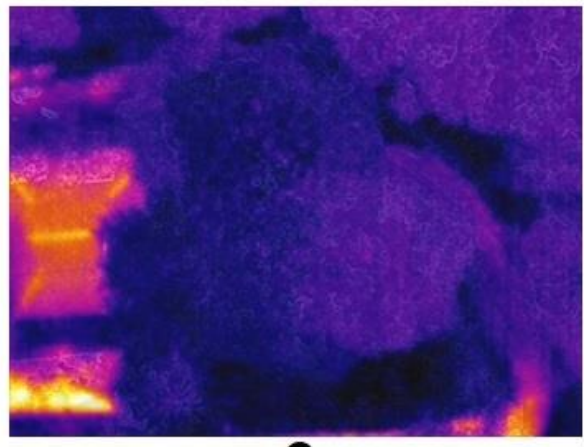

C

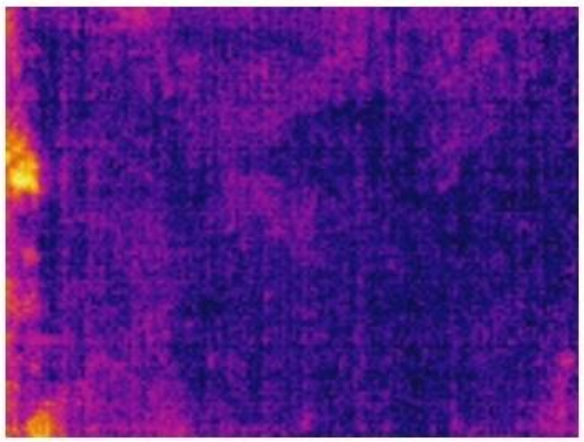

E

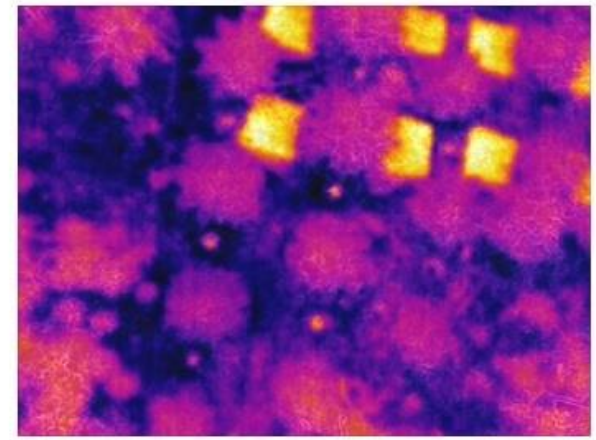

B
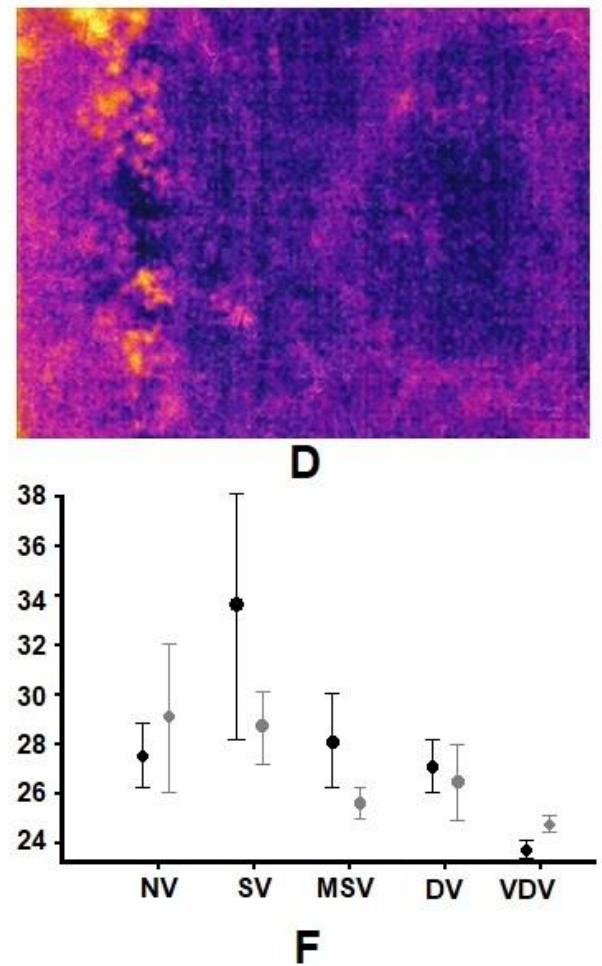

Fig. 5. Photo capture by drone on 15 August 2020 using a series of thermal infrared images taken at the same time of day from 17:00-17:15. An example of a thermal image is shown from (A) NP: Nonvegetation, (B) SV: Sparse vegetation, (C) MSV: Moderately sparse vegetation, (D) DV: Dense vegetation, (E) VDV: Very dense vegetation, and (F) Graph of min, mean and max temperature in each 
canopy cover classes at 17:00-17:15 (black line show the temperature in forest floor and grey line show the temperature in canopy) (Rahman and Setiawan, 2020).

\subsection{Challenges}

In general, two main factors are limiting the use of this tool in monitoring animals. The first is related to limitations on the tool's characteristics, and the second is related to environmental factors. Regarding the tool factor, the drones used in this research have FLIR with a lower resolution than the recommended standard, so it is quite difficult to identify animals capture by thermal sensors. Furthermore, drones are not recommended to be flown on autopilot at night; this is related to sensors that don't work optimally at night because they need light to regulate movement if there are obstacles around them. Besides that, in night flights, a pilot needs skill and experience and a detailed examination of the location at the time of landing.

For environmental factors, monitoring wildlife by drones is very dependent on weather conditions. UAV surveys cannot be carried out during rainy conditions or when visibility is limited due to fog. Strong wind conditions can also limit the use of this tool, which can cause the drone to lose control and cause the image captured by the drone to become blurry. Besides, strong winds can cool the animal's body, so it can be reducing detection since the temperature contrast between the animal, and its environment is reduced.

\section{Conclusion}

Surveys using drones with thermal sensors have their challenges, and this generally occurs in the application of new technologies for animal monitoring. However, this tool is promising for monitoring and researching the ecology of tropical rainforest animals. The researcher found this tool to work well in various canopy cover classes taking into account various parameters regarding drone flying height, noise level, temperature, and flight time of the drone. Increasing this tool's effectiveness for detecting animals can be done by conducting drone flights at an altitude of $<50 \mathrm{~m}$ HAGL and selecting a flight time in the early morning or evening when the ambient temperature drops drastically. Besides, a critical issue in using this tool during our tests was finding out how to identify the species from the resulting lowresolution thermal images.

\section{Acknowledgements}

The researcher is thankful to Prof. Lilik Budi Prasetyo from the Geospatial Modeling Laboratory, Faculty of Forestry and Environment IPB, for the equipment's kind assistance during the data collection. This study was funded by the Ministry of Education and Culture, Republic of Indonesia (Competitive National Primary Research of Higher Education (PDUPT) with contract number 1/AMD/E1.KP.PTNBH/2020).

\section{References}

1. N.M. Schroeder, A. Panebianco, R.G. Musso, P. Carmanchahi, An experimental approach to evaluate the potential of drones in terrestrial mammal research: a gregarious ungulate as a study model, R Soc Open Sci. 7, 1 (2020) https://doi.org/10.1098/rsos.191482

2. W.Y. Lee, M. Park, C-U. Hyun, Detection of two Arctic birds in Greenland and an endangered bird in Korea using RGB and thermal cameras with an unmanned aerial 
vehicle (UAV), PLoS ONE. 14, 9 (2019)

https://doi.org/10.1371/journal.pone.0222088

3. M. Lethbridge, M. Stead, C. Wells, Estimating kangaroo density by aerial survey: a comparison of thermal cameras with human observers, Wildl Res. 46, 8 (2019) https://doi.org/10.1071/WR18122

4. C. Patterson, W. Koski, P. Pace, B. McLuckie, and D.M. Bird, Evaluation of an unmanned aircraft system for detecting surrogate caribou targets in Labrador, Unmanned Veh Syst. 4, 1 (2016) https://doi.org/10.1139/juvs-2015-0014

5. J.F. McEvoy, G.P. Hall, P.G. McDonald, Evaluation of unmanned aerial vehicle shape, flight path and camera type for waterfowl surveys: disturbance effects and species recognition, PeerJ. 4, e1831 (2016) https://doi.org/10.7717/peerj.1831

6. J. Linchant, S. Lhoest, S. Quevauvillers, P. Lejeune, C. Vermeulen, J.S. Ngabinzeke, B.L. Belanganayi, W. Delvingt, P. Bouche, UAS imagery reveals new survey opportunities for counting hippos, PLoS ONE. 13, 11 (2018) https://doi.org/10.1371/journal.pone.0206413

7. M.A. Ezat, C.J. Fritsch, C.T. Downs, Use of an unmanned aerial vehicle (drone) to survey Nile crocodile populations: A case study at Lake Nyamithi, Ndumo game reserve, South Africa, Biol Conserv. 223, (2018)

https://doi.org/10.1016/j.biocon.2018.04.032

8. S.N. Longmore, R.P. Collins, S. Pfeifer, S.E. Fox, M. Mulero-Pázmány, F. Bezombes, A. Goodwin, M. De Juan Ovelar, J.H. Knapen, S.A. Wich, Adapting astronomical source detection software to help detect animals in thermal images obtained by unmanned aerial systems, Int J Remote Sens. 38, 8-10 (2017) https://doi.org/10.1080/01431161.2017.1280639

9. G.W. Croon, D.R. Mccullough, C.E. Olson Jr, L.E. Queal, Infrared scanning techniques for big game censusing, J Wildl Manage. 32, 4 (1968) https://doi.org/10.2307/3799549

10. B.S. Haroldson, E.P. Wiggers, J. Beringer, L.P. Hansen, J.B. McAninch, Evaluation of aerial thermal imaging for detecting white-tailed deer in a deciduous forest environment, Wildl Soc Bull. 31, 4 (2003) https://doi.org/10.2307/3784466

11. F. Potvin, L. Breton, Testing 2 aerial survey techniques on deer in fenced enclosures visual double-counts and thermal infrared sensing, Wildl Soc Bull. 33, 1 (2005)

12. J. Witczuk, S. Pagacz, A. Zmarz, M. Cypel, Exploring the feasibility of unmanned aerial vehicles and thermal imaging for ungulate surveys in forests - preliminary results, Int J Remote Sens. 39, 15 (2017) https://doi.org/10.1080/01431161.2017.1390621

13. C. Burke, M.F. Rashman, S.N. Longmore, O. McAree, P. Glover-Kapfer, M. Ancrenaz, S.A. Wich, Successful observation of orangutans in the wild with thermalequipped drones, J Unmanned Veh Syst. 7, 4 (2019) https://doi.org/10.1139/juvs2018-0035

14. J.T. Beaver, R.W. Baldwin, M. Messinger, C.H. Newbolt, S.S. Ditchkoff, M.R. Silman, Evaluating the use of drones equipped with thermal sensors as an effective method for estimating wildlife, Wildl Soc Bull. 44, 2 (2020) https://doi.org/10.1002/wsb.1090

15. Z. Święcicki, Instrukcja Urządzania Lasu. Cz. 1, Instrukcja Sporządzania Projektu Planu Urządzenia Lasu Dla Nadleśnictw, Warszawa: Centrum Informacyjne Lasów Państwowych (2012)

16. I. Jonckheere, S. Fleck, K. Nackaerts, B. Muys, P. Coppin, M. Weiss, F. Baret, Review of methods for in situ leaf area index determination: Part I. Theories, sensors and hemispherical photography, Agric for Meteorol. 121, 1-2 (2004) https://doi.org/10.1016/j.agrformet.2003.08.027 
17. A.H. Mustari, I. Zulkarnain, D. Rinaldi, Keanekaragaman jenis dan penyebaran mamalia di Kampus IPB Dramaga Bogor, Media Konservasi. 19, 2 (2014) https://doi.org/10.29244/medkon.19.2.\%25p

18. [Himakova] Himpunan Mahasiswa Konservasi Sumber Daya Hutan dan Ekowisata, Kampus Institut Pertanian Bogor Sebagai Kampus Biodiversitas (2016) http://himakova.lk.ipb.ac.id/kampus-institut-pertanian-bogor-sebagai-kampusbiodiversitas. [Accessed on 15 September 2020]

19. P. Christiansen, K.A. Steen, R.N. Jørgensen, H. Karstoft, Automated detection and recognition of wildlife using thermal cameras, Sensors. 14, 8 (2014) https://doi.org/10.3390/s140813778

20. L.F. Gonzalez, G.A. Montes, E. Puig, S. Johnson, K. Mengersen, K.J. Gaston, Unmanned aerial vehicles (UAVs) and artificial intelligence revolutionizing wildlife monitoring and conservation, Sensors. 16, 1 (2016) https://doi.org/10.3390/s16010097

21. Y. LeCun, Y. Bengio, G. Hinton, Deep learning, Nature. 521, 7553 (2015) https://doi.org/10.1038/nature14539

22. A.C. Seymour, J. Dale, M. Hammill, P.N. Halpin, D.W. Johnston, Automated detection and enumeration of marine wildlife using unmanned aircraft systems (UAS) and thermal imagery, Sci Rep. 7, 45127 (2017) https://doi.org/10.1038/srep45127

23. M.D. Wright, P. Goodman, T.C. Cameron, Exploring behavioural responses of shorebirds to impulsive noise, Wildfowl. 60 (2010) http://repository.essex.ac.uk/id/eprint/10293

24. E. Vas, A. Lescroel, O. Duriez, G. Boguszewski, D. Gremillet, Approaching birds with drones: first experiments and ethical guidelines, Biol Lett. 11, 2 (2015) https://doi.org/10.1098/rsbl.2014.0754

25. M. Mulero-Pázmány, R. Stolper, L.D. Van Essen, J.J. Negro, T. Sassen, Remotely piloted aircraft systems as a rhinoceros anti-poaching tool in Africa, PLoS ONE. 9, 1 (2014) https://doi.org/10.1371/journal.pone.0083873

26. R. Kays, J. Sheppard, K. Mclean, C. Welch, C. Paunescu, V. Wang, G. Kravit, M. Crofoot, Hot monkey, cold reality: surveying rainforest canopy mammals using dronemounted thermal infrared sensors, Int J Remote Sens. 40, 2 (2019) https://doi.org/10.1080/01431161.2018.1523580 